\title{
Orações causais e estrutura informacional da sentença*
}

Patrícia Rodrigues ${ }^{a}$

\section{Resumo}

Este trabalho investiga as orações causais do português brasileiro introduzidas por porque. $\mathrm{O}$ objetivo principal é mostrar que, para obter-se uma análise adequada dessas orações, é necessário levar em conta a estrutura informacional da sentença. Em geral, assume-se implicitamente que as orações causais próprias com porque são sempre focalizadas, $e$, por esse motivo, são analisadas como orações subordinadas de predicado. Este artigo mostra que é possivel atribuir diferentes estruturas informacionais a essas construções: ou (i) a construção causal é associada a uma única estrutura foco-pressuposição, em que a oração subordinante veicula a pressuposição, e a oração causal, o foco; ou (ii) a construção causal pode ser associada a duas estruturas focopressuposição distintas. Argumenta-se que, enquanto a análise como subordinada de predicado se aplica corretamente aos casos descritos em (i), essa análise não é adequada aos casos descritos em (ii). Conclui-se que a oração causal nesses casos deve ser analisada como uma oração subordinada de frase.

* Trabalho desenvolvido no pós-doutorado da UFRGS.

Palavras-chave: Orações causais. Estrutura informacional. Adjunção.

a Universidade Federal do Paraná. E-mail: rodriguespatriciaa@gmail.com. 


\section{Introdução}

O nexo lógico entre duas orações pode ser estabelecido por meio de diferentes conectores. Em português, as orações introduzidas pelas conjunções porque, que, pois, uma vez que, já que, visto que, como, etc. são, nas gramáticas tradicionais, analisadas ou como orações causais, ou como orações explicativas, dependendo do valor causal ou explicativo da conjunção. As conjunções causais são consideradas subordinativas e definidas como vocábulos que "iniciam uma oração subordinada denotadora de causa" (CUNHA; CINTRA, 2001, p. 605); e as conjunções explicativas são consideradas coordenativas e definidas como vocábulos "que ligam duas orações, a segunda das quais justifica a ideia contida na primeira" (CUNHA; CINTRA, 2001, p. 581). Os dados em (1) e em (2), com orações introduzidas pelo conector porque, ilustram essa distinção. A oração em (1) é analisada como uma oração subordinada adverbial causal, enquanto a oração em (2) é analisada como oração coordenada explicativa.

(1) Não veste com luxo [porque o tio não é rico]. (CUNHA; CINTRA, 2001, p. 605)

(2) Espere um pouco, [porque ele não demora]. (ROCHA LIMA, 1972, p. 186)

Como já observado em diversos estudos linguísticos (TRAVAGLIA, 1986; MUNIZ, 2000; LOBO, 2003, 2013; MATOS, 2004, 2006; ILARI, 2008, entre outros), essa descrição tradicional carece de clareza, além de ser circular: a oração é subordinada causal porque é encabeçada por uma conjunção subordinativa causal, e a conjunção é subordinativa causal porque inicia "uma oração subordinada denotadora de causa". Além disso, um mesmo conector, como porque, por exemplo, pode ser encontrado tanto na lista das conjunções subordinativas quanto na lista das conjunções coordenativas. Observa-se, ainda, que a correspondência biunívoca entre subordinação e coordenação, de um lado, e causa e explicação, de outro, não é possível de ser feita com base nos critérios estabelecidos pela descrição tradicional.

Contudo, mesmo reconhecendo vários problemas na caracterização tradicional dessas orações, os estudos linguísticos, de modo geral, acabam por adotar essa mesma 
distinção semântica em suas análises, especialmente no caso das orações com porque, uma conjunção que pode introduzir orações tanto causais quanto explicativas. Geralmente, as orações interpretadas como causa (3a) são analisadas como orações adverbiais modificadoras de predicado e as orações interpretadas como explicação (3b) são analisadas como orações que teriam uma menor integração sintática, sendo consideradas ora como coordenadas, ora como subordinadas de caráter mais apositivo ou periférico.

(3) a. A Maria foi embora porque o Pedro chegou.

b. A Maria saiu, porque as luzes estão apagadas.

O objetivo deste artigo é mostrar que a distinção "causais vs. explicativas" não é o melhor ponto de partida para o estudo das propriedades sintáticas das orações introduzidas pelo conector porque, pois a oração causal em (3a), além de adjunto de predicado, pode também funcionar como um adjunto de frase, o que neutralizaria a caracterização semântica na determinação da estrutura sintática.

Argumento que a análise da oração causal em (3a) como modificadora de predicado decorre da assunção implícita de que esse tipo de construção causal só pode ser associado a um determinado tipo de estrutura informacional (entendida como uma estrutura foco-pressuposição), em que a oração matriz representa a pressuposição, e a oração causal, o foco. No entanto, uma construção como (3a) também poderia ser interpretada de modo que a oração matriz e a oração causal formem duas estruturas foco-pressuposição separadas ${ }^{1}$. Defendo que, nessa configuração, a oração causal deve ser analisada como uma oração modificadora de frase.

O artigo está organizado como segue. A seção 1 apresenta a distinção clássica entre causais e explicativas, bem como as análises propostas para essas orações, e aponta para os problemas decorrentes de adotar-se essa classificação semântica como ponto de partida no estudo dessas construções. A seção 2 apresenta os pressupostos teóricos que embasam a discussão. A seção 3 discute as diferentes estruturas informacionais

1 Nesse caso, a sentença seria melhor representada com uma vírgula separando as duas orações. que podem ser atribuídas às construções causais e propõe análises com base nessas considerações. A seção 4 apresenta as considerações finais do trabalho. A principal contribuição 
deste estudo é mostrar que a abordagem sintática das orações introduzidas pelo conector porque a partir de uma perspectiva informacional pode ser mais produtiva.

\section{A distinção entre as orações causais}

\subsection{Orações causais próprias vs. orações causais explicativas}

Como discutido na introdução, os estudos linguísticos questionam as definições e os critérios apresentados nas gramáticas tradicionais para a classificação das orações causais e explicativas (TRAVAGLIA, 1986; MUNIZ, 2000; LOBO, 2003, 2013; MATOS, 2004, 2006; ILARI, 2008; entre outros). Ainda assim, de modo geral, esses estudos adotam essa mesma distinção semântica, muitas vezes com uma ligeira mudança terminológica: o conjunto formado pelas orações causais e explicativas recebe a denominação mais abrangente de "orações causais", que são subclassificadas em causais próprias e causais explicativas, com definições semelhantes (cf. QUIRK et al., 1985; LOBO, 2003; MATOS, 2004; entre outros). No caso das orações causais próprias, a relação causal diz respeito a uma relação entre eventos ou situações: a situação denotada na oração causal expressa a razão da situação denotada na oração principal. Nesse sentido, a relação causal é definida como direta (causa de re), e a conexão causal entre os eventos pode ser entendida ou como real, objetiva (4a), ou como resultado de uma inferência por parte do falante (4b), ou, ainda, como uma conexão estabelecida por uma dada motivação (4c) (cf. QUIRK et al. 1985).

(4) a. As flores murcharam porque ninguém regou.

b. O João regou as flores porque elas estavam secas.

c. O João regou as flores porque a Maria pediu.

Já as causais explicativas estabelecem uma relação causal que é frequentemente referida como indireta, ou seja, as orações explicativas não fornecem a causa da situação descrita na oração principal, como no caso da razão direta, mas expressam o motivo ou justificativa para a enunciação dessa oração (causa de dicto) (5). Em (5a), por exemplo, o falante conclui e afirma que 
a Maria está em casa com base em um argumento que consiste em (i) evidências sobre a verdade do conteúdo proposicional da oração causal e (ii) conhecimento sobre a plausibilidade de que a Maria estar em casa é a razão de seu carro estar na garagem. Ou seja, a oração causal fornece uma evidência para a conclusão expressa na principal. No caso de (5b), o falante ordena/pede a seu interlocutor que abra a porta e justifica esse pedido (um ato de fala) pelo fato de estar muito calor.

(5) a. A Maria está em casa, porque o carro dela está na garagem.

b. Abra a porta, porque está muito calor.

Em uma relação causal direta, fala-se em modificação de um evento, pois a oração causal acrescenta uma propriedade (a causa) ao evento denotado pela oração principal. Já em uma relação causal indireta, a oração causal modifica o ato inferencial que leva à conclusão expressa na oração principal ou o ato de fala expresso por essa oração. A distinção "causais próprias vs. causais explicativas" também é referida como "causais de enunciado" (4) vs. "causais de enunciação" (5) (LOPES, 2012), ou, ainda, tal como definido por Sweetser (1990), como "causais de conteúdo" (4) vs. "causais epistêmicas" (5a) e "causais de ato de fala" (5b).

No que diz respeito à estrutura dessas orações, há divergências com relação à análise das causais explicativas, que são consideradas ora como coordenadas (LOBO, 2003), ora como subordinadas de caráter mais apositivo ou periférico (MATOS, 2004, 2006), ou como orações que apresentam a maioria das características da subordinação, mas que estabelecem com a oração matriz uma ligação paratática (AGUIAR; BARBOSA, 2014; COLAÇO; MATOS, 2016a, 2016b). Já as orações causais próprias são invariavelmente analisadas como orações subordinadas (LOBO, 2003).

Em suma, de modo geral, os estudos linguísticos adotam a distinção clássica entre orações causais que expressam uma causa própria (causa de re) e orações causais que expressam uma causa explicativa (causa de dicto, que podem ainda ser desdobradas em causais epistêmicas e causais de ato de fala). Com base nessa distinção semântica inicial, procuram definir a estrutura sintática de cada tipo de oração. 
Esse é o caso, por exemplo, de Lobo (2003), que estuda as orações subordinadas adverbiais do português europeu. No caso das orações causais, a autora assume que não existe correspondência direta entre o funcionamento sintático e o valor semântico dessas orações e defende que a distinção entre elas deve basear-se em critérios formais. Para definir seu objeto de estudo, aplica às orações causais testes sintáticos que distinguem subordinadas de coordenadas. No entanto, no caso do conector porque, Lobo (2003) distingue orações introduzidas por um "porque causal" de orações introduzidas por um "porque explicativo". A autora utiliza, em seus testes, exemplos prototípicos de cada uma dessas classes de orações. Sua conclusão é que as orações com "porque explicativo" formariam estruturas coordenadas, ao contrário das orações com "porque causal", que formariam estruturas subordinadas. Consequentemente, dado seu objeto de estudo, apenas as orações consideradas causais próprias são investigadas em seu trabalho. Uma possível consequência dessa análise seria a necessidade de se assumir a existência de dois conectores porque no léxico, o que não seria desejável, dado que o conector propriamente dito não pode ser considerado ambíguo.

Esse também é o caso de Colaço e Matos (2016a, 2016b), que se propõem a estudar exclusivamente as causais explicativas. As autoras, no entanto, reconhecem que conectores com significado de explicação, que normalmente introduziriam orações explicativas, podem também denotar a causa real da situação expressa na oração principal, como na sentença em (6). As autoras constroem esse exemplo a partir do exemplo em (7), cuja oração causal é analisada por elas como uma causal própria.

(6) Hoje nevou, pois/que/porque/uma vez que a temperatura desceu abaixo dos $0^{\circ} \mathrm{C}$. (COLAÇO; MATOS, 2016a, p. 45, ex. (7))

(7) Hoje nevou porque a temperatura desceu abaixo dos $0^{0}$ C. (COLAÇO; MATOS, 2016a, p. 45, ex. (4))

Colaço e Matos (2016a) não aprofundam, contudo, a investigação sobre as possíveis diferenças entre (6) e (7), restringindo sua análise das orações explicativas aos casos que claramente possuem uma leitura de dicto. Assim, uma sentença como (6), cuja oração causal pode ser interpretada como causa própria, mas que possui, ao mesmo tempo, um 
"sabor" explicativo, não é contemplada nos estudos sobre as orações causais: nem em estudos sobre as orações causais próprias, como Lobo (2003), nem em estudos sobre as orações causais explicativas, como Colaço e Matos (2016a,2016b).

Em síntese, mesmo reconhecendo a existência de problemas ligados à distinção clássica "causal própria vs. causal explicativa", os autores, de modo geral, adotam essa distinção, restringindo-se ao estudo dos exemplos prototípicos de cada classe. Dados como o apresentado em (6), não sendo prototípicos, seriam deixados de lado. O que pretendo mostrar no presente trabalho é que essa distinção semântica não é o ponto de partida mais adequado para o estudo das orações causais, e que a estrutura informacional da sentença também deve ser levada em consideração. Desse ponto de vista, as orações causais próprias com porque podem receber não só a análise de adjunto de predicado, mas também a análise de adjunto de frase.

Para enquadrar essa discussão, apresento brevemente, na próxima seção, alguns pressupostos sobre os tipos de estruturas propostos para as orações adjuntas e sobre a estrutura informacional das sentenças. Em seguida, na seção 3, discuto a estrutura informacional das construções causais, bem como suas estruturas sintáticas correspondentes. Apresento também, na seção 3, a análise de Lobo (2003) com relação às orações causais próprias, que pode ser tomada como representativa das análises encontradas na literatura. Veremos que a análise de Lobo (2003) relativa às orações encabeçadas pelo conector porque é enviesada por uma assunção implícita sobre a estrutura informacional dessas construções e que, por esse motivo, acaba por não abarcar todas as ocorrências desse tipo de oração.

\section{Pressupostos teóricos}

2 C-comando é uma relação estrutural existente entre dois elementos em uma sentença. A definição em (i) é proposta por Mioto et al. (2013, p 56): "a c-comanda $\beta$ se e somente se $\beta$ é o irmão de a ou se $\beta$ é dominado pelo irmão de $\alpha^{\prime \prime}$.

\subsection{A posição estrutural das orações adjunto}

De acordo com Haegeman (2002, 2006), há uma distinção entre as orações adverbiais em termos do grau de integração dessas orações com relação à oração matriz. Com base em testes envolvendo a noção de c-comando ${ }^{2}$, como escopo da negação, de operadores de foco e de advérbios, a autora mostra que há 
duas classes de orações adverbiais: (i) aquelas que podem ser c-comandadas por elementos presentes na oração matriz e (ii) aquelas que não podem ser c-comandadas por elementos presentes na oração matriz. A autora propõe que as orações localizadas na área de c-comando da oração principal, que ela denomina de adverbiais centrais, seriam adjungidas no nível da projeção verbal (vP), e que as orações localizadas fora da área de c-comando da oração principal, as adverbiais periféricas, seriam adjungidas a CP (a projeção sintática que estabelece uma interface com a pragmática) ${ }^{3}$. Tipicamente, as adverbiais de modo, de tempo ou condicionais seriam centrais, e as concessivas seriam periféricas. As orações causais, como será discutido neste trabalho, podem ser centrais ou periféricas.

\subsection{Estrutura informacional}

As sentenças podem ser caracterizadas segundo sua Estrutura Informacional (EI), que é tradicionalmente definida como o "empacotamento" da informação veiculada em um enunciado. A EI reflete assim a forma como a informação é codificada linguisticamente segundo o que o falante acredita ser ou não compartilhado com seu interlocutor. Ou seja, visando à atualização das representações mentais de seu interlocutor, $\mathrm{o}$ falante decide que partes da sentença constituem informação velha ou informação nova, e seu enunciado é codificado em função dessa decisão. Haveria, minimamente, duas categorias linguísticas para operar esse processo, definidas de diferentes maneiras, de acordo com o modelo assumido para a EI. Por exemplo, a EI de uma sentença pode ser entendida como uma estrutura foco-pressuposição, em que a pressuposição é definida como a informação que o falante assume ser compartilhada entre ele e seu interlocutor, e o foco corresponde à informação nova, assertada pelo falante (cf. CHOMSKY, 1971; JACKENDOFF, 1972; entre outros).

Sem adotar um modelo específico para EI, este trabalho centrais também recebem na literatura as denominações de adverbiais de predicado, integradas ou não periféricas; e as adverbiais periféricas também são chamadas de adverbiais de frase. 
Alguns autores relacionam, no entanto, a EI de uma construção complexa à sua entoação e ao tipo de conexão sintática que se estabelece entre as orações. Frey e Truckenbrodt (2015), por exemplo, com base em Reis (1997) e Holler (2008), assumem que um enunciado complexo, quando formado por orações não integradas ou fracamente integradas entre si, não pode ser associado a uma única estrutura foco-background nem a uma única curva prosódica. Assim, as orações adverbiais periféricas, por estarem conectadas ao $\mathrm{CP}$, seriam parcialmente (ou fracamente) integradas à oração principal; um enunciado com orações desse tipo possuiria dois contornos prosódicos distintos, podendo também ser associado a duas estruturas foco-pressuposição distintas. Já uma adverbial central e sua oração matriz seriam integradas sintaticamente, e o enunciado todo possuiria um contorno prosódico único e corresponderia a uma única estrutura foco-pressuposição. A próxima seção discute as construções causais, relacionando suas EI com a integração sintática das orações.

\section{Estruturas informacionais e as orações causais}

\subsection{A EI das construções causais com porque}

Assumindo-se os pressupostos discutidos na seção anterior, é possível afirmar que as construções que apresentam uma relação causal podem ser associadas a estruturas informacionais distintas. Observem-se, em primeiro lugar, os exemplos ${ }^{4}$ em (8) e em (9), que apresentam orações causais próprias: tanto em (8B) como em (9B), a relação causal é interpretada como uma relação entre eventos, em que casar-se com separação de bens é a causa para não se receber uma herança.

(8) A: Eu fiquei sabendo que o João casou com uma milionária, e que, dois meses depois, ela morreu num acidente de avião. Me disseram que ele não recebeu um tostão furado de herança. Por que que ele não herdou nada?!

B: O João não herdou nada porque casou com separação de bens.

(9) A: Eu fiquei sabendo que o João casou com uma milionária, e que, dois meses depois, ela morreu num acidente de avião. O que aconteceu com ele? Ficou rico?

${ }_{4}$ Exemplos nossos.

B: O João não herdou nada, porque ele casou com separação de bens. 
Nas construções causais em (8B) e (9B), a ausência/ presença da vírgula marca a diferença de padrão informacional, que coincide com diferentes padrões de entoação. O exemplo (8B) possui um único contorno prosódico, e é possível atribuir ao enunciado todo uma única estrutura foco-pressuposição: a oração subordinante o João não herdou nada representa a pressuposição, e a oração adverbial porque casou com separação de bens representa o foco. Já (9B) possui dois contornos prosódicos, e as orações formam duas estruturas foco-pressuposição distintas. Mesmo que a informação veiculada na oração causal não tenha sido pedida pelo interlocutor, o falante considera pertinente acrescentar a causa da situação descrita na oração O João não herdou nada. Vale observar que (9B) não é adequada, por exemplo, como resposta à pergunta em (8A). Resumindo, as orações causais que veiculam uma causa própria podem apresentar graus de integração distintos com a relação à oração principal, e a sentença pode ser associada a EI distintas.

Observe-se agora os exemplos em (10), em que as sentenças podem veicular uma relação causal explicativa:

(10) a. Esta noite choveu, porque as ruas estão molhadas.

b. As ruas estão molhadas, porque esta noite choveu.

c. Feche a janela, porque está chovendo.

Em (10a), a rua molhada não pode ser a causa de ter chovido, assim a oração causal é interpretada como uma evidência para a enunciação da oração principal. O falante, com base na observação de que as ruas estão molhadas, conclui/ infere que choveu. A sentença em (10b) também pode ser interpretada como uma relação causal epistêmica, ou seja, a oração principal as ruas estão molhadas é enunciada como uma conclusão, uma inferência, não como um fato, e a proposição esta noite choveu, veiculada pela oração causal e assumida como verdade pelo falante, é apresentada como evidência para a conclusão enunciada. No entanto, nesse caso, a chuva pode ser uma causa para a rua estar molhada, assim, (10b) também poderia veicular uma relação causal própria. Fora de contexto, essa construção apresenta então uma ambiguidade: a oração causal pode modificar tanto o evento denotado na oração principal como a enunciação dessa oração (em outras palavras, pode modificar o ato inferencial). Já em (10c), a oração 
principal veicula um ato de fala injuntivo, e a oração causal é apresentada como justificativa para essa ordem/pedido. Nesses casos, não há possibilidade de ambiguidade, a oração causal está modificando o ato de fala.

Com relação à estrutura informacional dessas sentenças, só é possível postular que as duas orações que compõem a sentença têm, cada uma, sua própria estrutura focopressuposição. Em outras palavras, não é possível associar o enunciado como um todo a apenas uma estrutura focopressuposição, em que a oração principal represente a pressuposição, e a causal, o foco. Em primeiro lugar, essas construções apresentam dois contornos prosódicos distintos. Em seguida, a oração principal não pode ser identificada com a pressuposição em uma estrutura foco-pressuposição: em (10a) e (10b) a oração principal veicula uma conclusão, e uma conclusão não pode ser considerada uma informação compartilhada entre os interlocutores; em (10c), da mesma forma, não se pode assumir como conhecimento compartilhado o ato de fala em execução veiculado pela oração principal. Ou seja, uma oração que denote uma causa explicativa só pode ocorrer em sentenças cuja matriz veicula um ato de fala independente, seja uma asserção seja uma injunção.

Em síntese, a estrutura das orações causais introduzidas pelo conector porque não pode ser determinada considerandose apenas a distinção semântica causa vs. explicação, pois há casos em que orações causais próprias apresentam graus de integração diferentes em relação à oração principal ((8B) e (9B)) e casos em que a oração causal apresenta leituras distintas, como (10b). De acordo com Frey (2016), essa relativa liberdade de interpretação seria indicativa de menor integração sintática da oração causal. Assim, considerando que o grau de integração entre as orações está correlacionado com a EI, essa estrutura deve ser levada em conta na análise das construções causais. Duas possibilidades, em princípio, se apresentam: (i) a construção pode ser associada a uma única estrutura focopressuposição; (ii) a construção pode ser associada a duas estruturas foco-pressuposição distintas. Nos casos descritos em (i), a oração causal só pode denotar uma causa própria, mas nos casos descritos em (ii), a oração causal pode denotar tanto uma causa própria como uma causa explicativa. 


\subsection{A sintaxe das orações causais com porque}

\subsubsection{Adverbiais centrais e adverbiais periféricas}

Retomando o que foi exposto na seção 2, vimos que, nas construções complexas associadas a uma única estrutura foco-pressuposição, as orações adverbiais são integradas à oração principal e podem ser analisadas como adjungidas no nível de vP, pois estariam no domínio de c-comando da oração matriz. Por outro lado, há construções complexas que podem ser associadas a duas estruturas foco-pressuposição distintas, casos em que as orações adverbiais estariam mais fracamente integradas à oração principal: por não figurarem no domínio de c-comando da oração matriz, essas orações são analisadas como adjungidas ao nível de CP.

No caso das construções causais, vimos que elas podem ser associadas tanto a uma única estrutura foco-pressuposição como a duas estruturas foco-pressuposição distintas. Levando em conta a noção de integração sintática relacionada a essas diferentes estruturas informacionais, assumo que as orações causais com porque podem então ser analisadas tanto como uma oração adjunta de predicado (vP) como uma oração adjunta de frase $(\mathrm{CP})$. O que determina o nível da adjunção não é a distinção semântica "causal própria vs. causal explicativa", mas a estrutura informacional da sentença.

Assim, as orações causais próprias com porque, que podem figurar nos dois tipos de EI discutidos, poderiam ser tanto adjuntos de predicado quanto adjuntos de frase. Já as causais explicativas, que só podem figurar em construções com duas estruturas foco-pressuposição distintas, só poderiam ser adjuntos de frase. Os exemplos ${ }^{5}$ de (11) a (13), em que se observam os efeitos do Princípio $C$, mostram que, nas construções causais com uma estrutura foco-pressuposição única, a oração adverbial está no domínio de c-comando da oração matriz (11) e que, nas construções causais com duas estruturas foco-pressuposição, a oração adverbial está fora do domínio de c-comando da oração matriz (12)-(13).

(11) A: Eu fiquei sabendo que o João casou com uma milionária, e que, dois meses depois, ela morreu num acidente de avião. Me disseram que ele não recebeu um

Exemplos nossos. tostão furado de herança. Por que que ele não herdou nada?! 
B: *Ele ${ }_{i}$ não herdou nada porque o João casou com separação de bens ${ }^{6}$.

(12) A: Eu fiquei sabendo que o João casou com uma milionária, e que, dois meses depois, ela morreu num acidente de avião. O que aconteceu com ele? Ficou rico?

B: Ele ${ }_{i}$ não herdou nada, porque o João ${ }_{i}$ casou com separação de bens.

(13) A: Eu queria ir visitar a Maria, mas estou vendo que o carro dela não está na garagem. Será que ela está em casa?

B: Ela $a_{i}$ deve ter saído, porque a Maria ${ }_{\mathrm{i}}$ não anda a pé.

De acordo com o Princípio C da Teoria da Ligação (CHOMSKY, 1981), um pronome não pode ter como correferente uma Expressão-R por ele c-comandada. Em (11B), a oração causal não aceita, na posição de sujeito, uma Expressão-R correferenciada com um pronome sujeito na oração subordinante. No caso de (12B) e de (13B), essa correferenciação é possível. Em (11B), há então violação do Princípio $C$, o que indica que a oração causal está adjungida no domínio de c-comando do sujeito da oração principal. Em (12B) e (13B), não há violação do princípio C, o que indica que a oração causal está fora do domínio de c-comando do sujeito da oração principal. Note-se que a relação causal é própria em (12B) e explicativa em (13B).

Esses dados mostram que não há uma distinção em termos sintáticos entre orações com porque causal de um lado e orações com porque explicativo de outro, como proposto por Lobo (2003), pois tanto as orações causais como as explicativas podem ser analisadas como adjuntas a CP (12)-(13). A próxima seção discute a análise de Lobo (2003) em mais detalhes.

\subsubsection{A análise de Lobo (2003)}

Em seu estudo sobre as orações adverbiais do português europeu, Lobo (2003) considera, como visto na seção 1, apenas as orações causais próprias, que seriam subordinadas. Nessa classe, a autora distingue as orações introduzidas por porque das orações introduzidas por outros conectores - já que, visto

6 O índice $i$ subscrito indica que as duas expressões possuem o mesmo referente. que, dado que, uma vez que e como. As orações encabeçadas por porque são analisadas como subordinadas centrais, adjungidas a uma projeção interna à projeção de tempo (TP), e as orações 
encabeçadas pelos outros conectores são analisadas como subordinadas periféricas, adjungidas a projeções externas a TP.

Para distinguir as orações adverbiais centrais das orações adverbiais periféricas, Lobo (2003) utiliza testes sugeridos principalmente em Quirk et al. (1985), relacionados ao comportamento sintático das orações; os principais testes utilizados envolvem clivagem, pergunta $\mathrm{WH}$ - e escopo da negação e de advérbios focalizadores.

O fato de uma oração adverbial poder ser clivada, servir de resposta a uma pergunta $\mathrm{WH}$ - e recair sob o escopo da negação e de advérbios focalizadores indicaria que a oração é uma adverbial central, pois essas propriedades mostram que a oração é focalizada, e essa seria uma propriedade de orações adjuntas a uma posição baixa na estrutura da sentença, interna a TP. Resultados opostos indicariam que a oração não seria focalizada e não poderia, assim, ser analisada como uma adverbial central. A hipótese defendida por Lobo (2003) é que a oração seria ainda uma subordinada adverbial, mas periférica, adjungida a uma posição mais alta na estrutura da sentença, externa a TP.

Observem-se como exemplos as sentenças em (14) e em (15), retiradas de Lobo (2003, p. 151-152). As sentenças em (14b-e) mostram os resultados para esses testes aplicados à sentença em (14a), em que a oração causal é introduzida pelo conector porque, enquanto as sentenças em (15b-e) mostram os resultados para esses testes aplicados à sentença em (15a), em que a oração causal é introduzida pelo conector uma vez que. Os testes em (b-e) dizem respeito, respectivamente, à clivagem, à pergunta WH-, à negação e ao escopo de advérbios focalizadores, como só.

(14) a. O Zé faltou à aula porque estava doente.

b. Foi porque estava doente que o Zé faltou à aula.

c. Por que é que o Zé faltou às aulas? Porque estava doente.

d. O Zé não faltou à aula porque estava doente. (Faltou por outra razão)

e. O Zé só faltou à aula porque estava doente.

(15) a. O Zé faltou à aula, uma vez que estava doente.

b. *Foi uma vez que estava doente que o Zé faltou às aulas. doente.

c. Por que é que o Zé faltou às aulas? *Uma vez que estava 
d. *O Zé não faltou à aula uma vez que estava doente. (Faltou por outra razão)

e. *O Zé só faltou à aula uma vez que estava doente.

Os resultados em (14b-e), todos aceitáveis, indicam que a oração causal porque estava doente em (14a) deve estar conectada à matriz em uma posição baixa, interna a TP. Já os resultados em (15b-e), todos inaceitáveis, indicam que a oração causal uma vez que estava doente está ligada à matriz em uma posição alta, externa a TP. Dessa forma, na análise de Lobo (2003), a oração causal em (14a) seria uma adverbial central, enquanto a oração causal em (15a) seria uma adverbial periférica.

Lobo (2003) ainda associa a distinção entre adverbiais centrais e adverbiais periféricas a uma distinção entre suas propriedades discursivas, pois os testes acima estariam relacionados com a possibilidade de focalização da oração adverbial, no sentido de que as adverbiais periféricas, ao contrário das adverbiais centrais, não podem ser focalizadas (como mostram os exemplos em (15b-e)). Para Lobo (2003), o fato de as adverbiais periféricas não poderem ser focalizadas indicaria que, pelo menos em alguns casos, que incluem as causais, essas orações teriam um caráter inerentemente pressuposicional ${ }^{7}$, ao contrário das adverbiais centrais, que seriam subespecificadas para esse traço.

A hipótese da autora é que esse caráter pressuposicional das adverbiais esteja codificado nos conectores, ou seja, "o estatuto sintáctico e discursivo das duas classes de adverbiais estaria de certa forma relacionado com propriedades lexicais de seus conectores" (LOBO, 2003, p. 182). Assim, conectores causais como uma vez que, visto que, já que, dado que, e como seriam lexicalmente especificados como pressuposicionais, o que impediria a focalização da oração causal, que ocuparia então uma posição periférica na sentença. Por outro lado,

${ }^{7}$ Lobo (2003, p. 176) define 'pressuposição' como "informação que envolve conhecimento não necessariamente f o r m a 1 i z a d o linguisticamente que é tomado como 'dado adquirido', assumido como verdadeiro no momento da enunciação." o conector porque seria subespecificado para o traço de pressuposicionalidade, o que permitiria a focalização da oração causal (como mostram os testes em (14b-e)), seguindo-se assim a análise dessas orações como adverbiais centrais, que é a análise geralmente assumida na literatura para as orações causais próprias introduzidas pelo conector porque.

O problema dessa análise é que ela não discute a estrutura informacional da sentença como um todo, concentrando-se 
apenas nas propriedades discursivas da oração causal. De fato, se um conector é inerentemente pressuposicional, como uma vez que, a oração que ele introduz não pode ser focalizada. No caso do conector porque, no entanto, não especificado lexicalmente como pressuposicional, espera-se, naturalmente, que a oração que ele introduz possa veicular uma informação nova, não compartilhada, o que permitiria a focalização da oração, como assumido por Lobo (2003). O problema é que, aparentemente, para Lobo (2003), essa é a única possibilidade de análise para as orações com porque que expressam uma causa própria. $\mathrm{Ou}$ seja, ao assumir que a oração causal com porque é focalizada, Lobo (2003) assume também que a oração matriz veicula uma pressuposição e atribui, implicitamente, às construções causais próprias com porque uma única estrutura foco-pressuposição, em que a oração matriz representa a pressuposição, e a oração causal, o foco. Nessa perspectiva, as orações causais próprias introduzidas pelo conector porque só podem ser analisadas como adverbiais centrais, uma análise assumida por Lobo (2003), e também na literatura de modo geral.

No entanto, como discutido acima, uma construção causal própria que apresenta o conector porque poderia também ser formada por duas estruturas foco-pressuposição distintas, caso em que a oração causal não poderia ser analisada como uma adverbial central, pois não representaria o foco da sentença.

É possível afirmar, então, que há um viés na análise de Lobo (2003), no sentido de assumir implicitamente apenas uma EI possível para as construções causais próprias com porque. É interessante observar que esse viés na análise está, de certa forma, por trás da associação assumida na literatura entre causais próprias e orações subordinadas de um lado e causais explicativas e orações com menor integração sintática de outro, pois, se uma oração causal própria com porque é sempre analisada como uma oração focalizada, sintaticamente ela será necessariamente uma oração adjunta de predicado. Uma construção causal com uma oração explicativa, ao contrário, como discutido na seção 2, só pode ser associada a duas estruturas foco-pressuposição separadas, o que leva à análise da causal como uma oração com menor integração sintática em relação à oração principal.

Por conseguinte, segue-se a assunção corrente nos estudos em geral de que as causais próprias com porque 
são subordinadas adverbiais centrais, enquanto as causais explicativas teriam um estatuto menos integrado. Alguns autores, no entanto, como Colaço e Matos (2016a, 2016b), mencionam exemplos como (6), repetido abaixo como (16), que não se ajustariam a essa análise. Nesse exemplo, apesar de a oração causal poder denotar a causa real da situação expressa na oração principal, exatamente como no exemplo (7), repetido abaixo como (17), os conectores que podem introduzi-la possuiriam um significado de explicação, pois são, na maioria, conectores que normalmente introduziriam orações de dicto.

(16) Hoje nevou, pois/que/porque/uma vez que a temperatura desceu abaixo dos $0^{\circ} \mathrm{C}$. (COLAÇO; MATOS, 2016a, p. 45, ex. (7))

(17) Hoje nevou porque a temperatura desceu abaixo dos $0^{0}$ C. (COLAÇO; MATOS, 2016a, p. 45, ex. (4))

Vale notar, no entanto, que os dados em (16) e (17) apontam para a diferença entre as causais próprias discutidas na seção anterior. Interessantemente, as orações matriz e causal em (17), ao contrário das orações matriz e causal em (16), não aparecem separadas por uma vírgula. Supondo que as autoras utilizam a vírgula para marcar dois contornos prosódicos em (16), mas apenas um em (17), essa diferença pode ser relacionada à estrutura informacional das sentenças: a sentença em (17) seria associada a uma única estrutura foco-pressuposição, enquanto a sentença em (16) seria associada a duas estruturas foco-pressuposição distintas.

Em suma, as construções que apresentam uma relação causal própria mediada pelo conector porque possuem interpretações distintas, de acordo com sua estrutura informacional. Este artigo defende que a hipótese geralmente assumida na literatura, de que essas orações estariam adjungidas a uma projeção interna a TP, representa apenas uma das possibilidades de análise, adequada aos casos em que a EI da sentença corresponde a uma única estrutura focopressuposição. Nos casos em que as sentenças podem ser associadas a duas estruturas foco-pressuposição, as orações causais estariam adjungidas a uma projeção mais alta. Dessa forma, partindo-se da EI da sentença para analisar as orações causais, exemplos como (16) deixariam de representar um problema no caso de a oração causal ser introduzida por porque: a primeira oração hoje nevou possui sua própria estrutura 
foco-pressuposição, bem como a oração causal porque a temperatura desceu abaixo dos $0^{\circ} C$; a oração causal então, ainda que denotando uma causa própria, não poderia ser analisada como uma adverbial central.

Nesse sentido, vale lembrar que, como observado por Frey (2016), uma menor integração sintática permitiria uma maior liberdade interpretativa da oração; isso pode ser observado na construção em (16), que, além da leitura de causa própria, também apresenta uma leitura de explicação: o falante conclui que nevou e apresenta como evidência para essa conclusão o fato de a temperatura ter descido abaixo de zero. Trabalhos futuros devem determinar as diferenças entre porque e os outros conectores em (16). Além disso, é necessário aprofundar a discussão realizada neste artigo no sentido de saber se é possível diferenciar as orações causais próprias periféricas das orações causais explicativas periféricas. Ou seja, outra questão a ser respondida em trabalhos futuros é por que orações que, em princípio, modificam eventos ou situações poderiam ser adjungidas ao $\mathrm{CP}$ da oração principal.

\section{Considerações Finais}

Este artigo examinou orações causais do português brasileiro introduzidas pelo conector porque, com o objetivo de mostrar que essas orações só podem ser adequadamente analisadas quando se considera a estrutura informacional da sentença.

Argumentei que a análise como oração subordinada central geralmente proposta para as orações causais próprias tem como base a assunção implícita de que essas orações sempre representam o foco em uma estrutura foco-pressuposição. Mostrei que estruturas informacionais distintas podem ser atribuídas às construções causais e defendi que, ainda que a análise como subordinada central se aplique corretamente às orações integradas, essa análise não seria adequada aos casos em que a oração adverbial é parcialmente integrada. Nesses casos, a oração causal deve ser analisada como uma oração periférica.

Essa discussão leva à conclusão de que a distinção clássica entre causais próprias e causais explicativas comumente adotada nos estudos linguísticos não é suficiente para explicar todas as ocorrências das orações causais. 


\section{REFERÊNCIAS}

AGUIAR, J; BARBOSA, P. Establishing causal relations in European Portuguese: coordination and subordination in a stratified corpus. In: PRATAS F.; PEREIRA S.; PINTO C. (Org.). Coordination and Subordination.. Newcastle upon Tyne: Cambridge Scholars Publishing. 2014. p. 1-22.

CHOMSKY, N. Deep structure, surface structure and semantic interpretation. In: STEINBERG, D.; JAKOBOVITS, L. (Ed.). Semantics: an interdisciplinary reader in philosophy. Cambridge: CUP, 1971.

. Lectures on government and binding. Dordrecht: Foris. 1981.

COLAÇO, M.; MATOS, G. Explicative clauses in Portuguese as a case of parentheses. In: FiÉIS, A.; Lobo, M.; Pereira, S. (Org.). Romance languages and Linguistic Theory: Selected papers from Going Romance 28. p. 43-60. Amsterdam/ Philadelphia: John Benjamins. 2016a.

A natureza paratática das causais explicativas em português. Revista da Associação Portuguesa de Linguística, n. 1, p. 233-259, 2016b.

CUNHA, C.; CINTRA, L. 2001. Nova Gramática do Português Contemporâneo. Rio de Janeiro: Nova Fronteira.

FREY, W. On some correlations between interpretative and formal properties of causal clauses. In REICH, I.; SPEYER, A. (Ed.). Co- and subordination in German and other languages. Hamburg: Buske, 2016. p. 153-179.

;TRUCKENBRODT, H. Syntactic and prosodic integration and disintegration in peripheral adverbial clauses and in right dislocation/afterthought. In: TROTZKE, A.; BAYER, J. (Org.). Syntactic Complexity across Interfaces. Berlim: de Gruyter, 2015. p. 75-106.

HAEGEMAN, L. Anchoring to Speaker, adverbial clauses and the structure of CP. Georgetown University Working Papers in Theoretical Linguistics, v. 2, p. 117-180. 2002. 
Conditionals, factives and the left periphery. Lingua, Amsterdã, v. 116, n. 10, out. p. 1651-1669. 2006.

HOLLER, A. German dependent clauses from a constraintbased perspective. In: FABRICIUS-HANSEN, C.; RAMM, W. (Org.). Subordination vs. coordination in sentence and text. Amsterdam: Benjamins. 2008. p. 187-216.

ILARI, R. As conjunções. In: ILARI, R.; MOURA NEVES, M. H. (Org.). Gramática do Português culto falado no Brasil. Volume 2. Classes de palavras e processos de construção. Campinas: Editora Unicamp. 2008. p. 809-860.

JACKENDOFF, R. Semantic interpretation in generative grammar. Cambridge, MA: MIT Press, 1972.

LOBO, M. Aspectos da Sintaxe das orações subordinadas adverbiais do Português. 2003. 452f. Tese (Doutorado em Linguística) Universidade Nova de Lisboa, Lisboa.

.Subordinação Adverbial. In:RAPOSO, E; NASCIMENTO, M. F.; MOTA, M. A.; SEGURA L.; MENDES, A. (Org.) Gramática do Português, Lisboa: Fundação Calouste Gulbenkian. 2013. V. 2, cap. 34, p. 1981-2057.

LOPES, A. C. M. Contributos para uma análise semânticopragmática das causais de enunciação no português europeu contemporâneo. Alfa, v. 56, n. 2, p. 451-468, 2012.

MATOS, G. Coordenação Frásica vs. Subordinação Adverbial. In: FREITAS, T.; MENDES, A. (Org.) Actas do XIX Encontro Nacional da Associação Portuguesa de Linguística. Lisboa: APL, p. 555-567. 2004.

Coordination de phrases vs. subordination adverbiale - propositions causales en portugais. In BRILL, I.; REBUSCHI G. (Org.). Faits de Langue, Le Mans, v. 28, p. 169-180. 2006.

MIOTO, C. et al. Novo manual de sintaxe. São Paulo: Contexto, 2013.

MUNIZ, A. Sobre orações causais e explicativas. 2000. 88 f. Dissertação (Mestrado em Linguística) - Universidade de Brasília, Brasília. 
QUIRK, R. et al. A Comprehensive Grammar of the English Language. London: Longman. 1985.

REIS, M. Zum syntaktischen Status unselbständiger VerbzweitSätze. In: GEBURTSTAG, C. D.; RAMERS, K.-H. (Org.). Sprache im Fokus: Festschrift fur Heinz Vater zum 65. Tübingen: Niemeyer. 1997. p. 121-144.

ROCHA LIMA, C. H. Gramática normativa da língua portuguesa. Rio de Janeiro: Editora José Olympio. 1972.

SWEETSER, E. From etymology to pragmatics. Cambridge: Cambridge University Press. 1990.

TRAVAGLIA, L. C. Da distinção entre orações coordenadas explicativas e orações subordinadas adverbiais causais: uma questão sintática, semântica ou pragmática? Letras E Letras, Uberlândia, v. 2, n. 2, p. 241-286, jul. /dez. 1986. 


\section{Abstract \\ Causal clauses and information structure of the sentence}

This paper investigates Brazilian Portuguese causal clauses introduced by porque. The objective is to show that, to obtain an adequate analysis of these clauses, the information structure of the sentence must be considered. It is generally assumed that proper causal clauses with porque are always focused; for that reason, they are analyzed as central subordinate clauses. This paper shows that it is possible to assign different information structures to these constructions: (i) the causal construction is associated to a single focus-presupposition structure, in which the main clause conveys the presupposition and the causal clause, the focus; or (ii) the causal construction is associated to two distinct focus-presupposition structures. It is argued that, while the analysis as a central subordinate applies correctly to the cases described by (i), this analysis is not appropriate for the cases described by (ii). The conclusion is that this kind of causal clauses should be analyzed as peripheral adverbial clauses.

Key-words: Causal clauses. Information structure. Adjunction. 